[Araştırma Makalesi / Research Article ]

\section{KU ŨNamonu Eğitim Dergisi Kastamonu Education Journal}

Ocak 2019 Cilt:27 Sayı:1

kefdergi.kastamonu.edu.tr
Başvuru Tarihi/Received: 09.01.2018

Kabul Tarihi/Accepted: 30.03.2018 DOI: $10.24106 /$ kefdergi. 2543

\title{
2012 ve 2017 Bilişim Teknolojileri ve Yazılım Dersi Öğretim Programlarının Karşılaştırılması
}

\section{Comparison of Informatics Technologies and Software Development Course Curricula in 2012 and 2017}

\section{Öz}

\author{
Güler KARAMAN ${ }^{1}$, Umut KARAMAN ${ }^{2}$
}

Teknolojinin ilerlemesi ve çağa ayak uydurma gibi nedenlerle birçok alanda gerçekleşen toplumsal değişimler eğitim alanında da kendini göstermektedir. Eğitim tarihimize baktığımızda zaman zaman ders programlarında değişikliklere gidildiği görülmektedir. Bu bağlamda Milli Eğitim Bakanlığı (MEB) Talim ve Terbiye Kurulu Başkanlığı, 2017 yılında Ortaokul Bilişim Teknolojileri ve Yazılım (BTY) Dersi Öğretim Programı’nda yenilemeye gitmiştir. Bilindiği üzere program geliştirme dinamik bir süreçtir. Yeni programların, önceki programlar ile karşılaştırılması, araştırmacılara, alan uzmanlarına ve öğretmenlere yeni programın durumu ve niteliği hakkında bir perspektif sunar. Bu çalışma 2017-2018 eğitim öğretim yılında uygulamasına başlanan yeni Bilişim Teknolojileri ve Yazııım Dersi öğretim programını değişik yönleriyle incelemeyi amaçlamaktadır. Araştırmada elde edilen verilerde doküman incelemesi tekniği kullanılmıştır. Bu inceleme yapılırken programın önceki programla yaklaşım, genel amaç, öğrenme alanları, kazanım ve ölçme değerlendirme yaklaşımı açısından karşılaştırılması yapılmış, programın uygulamasında yaşanabilecek sorunlar ele alınmıştır. Bilişim Teknolojileri ve Yazılım Dersi 2012 ve 2017 öğretim programları bu araştırmanın veri kaynağını oluşturmaktadır. Araştırmanın sonucunda standart tabanlı öğretim programı anlayışından vazgeçildiği ve tüm sınıf düzeyleri için ayrı ayrı üniteler ve kazanımlar oluşturulduğu görülmüştür. 2017 Bilişim Teknolojileri ve Yazılım Dersi öğretim programıyla birlikte bilişim teknolojileri ve yazıım dersinin genel amaçlarının daha iyi ifade edildiği, içeriğin net olarak belirlenerek okullar arasındaki öğrenme farklılıklarının ortadan kaldırılmaya çalışıldığı, bilişim teknolojileri sınıf olmayan ve alt yapı problemi yaşayan okullar için kağıt-kalem etkinlikleri ve robotik kitler vb. farklı yaklaşımlar kullanılabileceği önerilerek ders işlenişinin öğretmene bırakıldığı görülmüştür. Ayrıca 2017 Bilişim Teknolojileri ve Yazılım Dersi öğretim programında dersin 1-4. sınıflar için öğrenci ve veli istekleri doğrultusunda, öğrencilerin hazır bulunuşluk ve öğretmenlerin bireysel beceri düzeylerine bağlı olarak serbest etkinlik ders saati içerisinde uygulanabileceği belirtilmiştir. 1-4. sınıflar için dersin seçmeli ve uzman öğretmeni tarafından verilmeyecek olmasının, programın uygulamasında yaşanabilecek sorunlardan en önemlisi olduğu düşünülmektedir.

Anahtar Kelimeler: Bilişim teknolojileri, yazılım, ders, öğretim programı, karşılaştırma, 2012,2017.

\section{Abstract}

The The social changes in many areas thanks to the progress of technology and modernization also manifest themselves in the field of education. Especially, developments in the field of informatics technologies necessitate that these developments would be utilized in the curriculum. In this context, Board of School affiliated to Ministry of National Education (MoNE) renewed the Secondary School Informatics Technologies and Software Development (ITSD) Course Curriculum. As it is known, curriculum development is a dynamic process. The comparison of new curricula with previous curricula provides a perspective to researchers, field specialists, and teachers about the status and nature of the new curriculum. This study is a descriptive screening study aiming to examine thoroughly the new ITSD curriculum which was launched to be implemented in 2017- 2018 academic year. A document review technique was used for the data obtained in the study. The curriculum was compared to the previous one in terms of approach, general objectives, learning areas, achievement, and assessment and evaluation approach and problems that could be experienced in the implementation of the curriculum were discussed. The data source of this study is Informatics Technologies and Software Course curricula belonging to 2012 and 2017 As a result of the study, it was found out that standards-based curriculum understanding was left with Informatics Technologies and Software Development Course curriculum in 2017 and separate units and achievements were generated for each grade. It was suggested that the general objectives of the informatics technologies and software development course are better expressed, the differences between the schools are tried to be eliminated by defining its content clearly, and teachers are offered three different approaches for teaching. Moreover, it is stated that the course can be applied for 1-4th graders within the free activity class time depending on student and parental desire and based on the readiness of students and individual proficiency level of teachers. It is considered that the most important of the problems can be experienced in the implementation of the program is that the courses will not be given as an elective and by an expert teacher for the classes.

Keywords: Informatics Technology, software, course, curriculum, comparison, 2012, 2017.

1. Keçiören Kardeşler Cumhuriyet Ortaokulu, Ankara, Türkiye; https://orcid.org/0000-0001-5713-6759

2. Milli Eğitim Bakanlığı, Din Öğretimi Genel Müdürlüğü, Ankara, Türkiye; https://orcid.org/0000-0001-7643-7266

Atıf / Citation: Karaman, G., \& Karaman, U. (2019). 2012 Ve 2017 bilişim teknolojileri ve yazılım dersi öğretim programlarının karşılaştırılması. Kastamonu Education Journal, 27(1), 309-318. doi:10.24106/kefdergi.2543 


\section{Extended Abstract}

The social changes that take place in many areas due to the progress of technology and the modernization also manifest itself in the field of education. Especially, developments in the field of informatics technologies necessitate that these developments would be utilized in the curriculum. In this context Board of School affiliated to Ministry of National Education (MoNE) renewed the Secondary School Informatics Technologies and Software Development (ITSD) Course Curriculum. As it is known, curriculum development is a dynamic process. The comparison of new curricula with previous curricula provides a perspective to researchers, field specialists, and teachers about the status and nature of the new curriculum. This study is a descriptive screening study aiming to examine thoroughly the new ITSD curriculum which was started to be implemented in 2017- 2018 academic year. A document review technique was used for the data obtained in the study.

The purpose of the study is to compare Informatics Technologies and Software Development Course curricula published by the Ministry of National Education in 2012 and 2017 in terms of the dimensions of approach, general objectives, learning areas, acquisitions, and assessment and evaluation approach.

The research questions of the study are as follows:

1. How were the dimension of approach discussed in the Informatics Technologies and Software Development Course curricula published in 2012 and 2017?

2. How were the dimension of general objectives discussed in the Informatics Technologies and Software Development Course curricula published in 2012 and 2017?

3. How were the dimension of learning areas discussed in the Informatics Technologies and Software Development Course curricula published in 2012 and 2017 ?

4. How were the dimension of acquisition discussed in the Informatics Technologies and Software Development Course curricula published in 2012 and 2017?

5. How were the dimension of assessment and evaluation discussed in the Informatics Technologies and Software Development Course curricula published in 2012 and 2017?

Findings

- Curriculum of Informatics Technologies and Software Development Course which was taught as a must course for 5th and 6th graders and elective course for 7th and 8th graders in 2012 was prepared within "standardsbased curriculum" understanding and it was found out that the taxonomy which was created by Tomei for technology while acquisitions were generated based on the standards. On the other hand, a unit-based approach was utilized for the curriculum of Informatics Technologies and Software Development Course which was developed for 1-4th, 5th, 6th, 7th, and 8th graders in 2017. There are total 5 units in the curriculum for 1-4th and 5-8th graders.

- In Informatics Technologies and Software Development Course Curriculum in 2017, it is important not only to set an integrity between informatics technology units but also with other subjects and real life, so that it is important to realize the discourses in real life, such as "students benefit from informatics technologies and software development course", "it is important to learn how to use technology appropriately", and "coding course is critical for the future of our country". Considering this information, it is noteworthy that the general objectives of the Informatics Technologies and Software Development course curriculum in 2017 were better expressed in the context of the general objectives of Turkish National Education

- When Informatics Technologies and Software Development course curricula in 2012 and 2017 are examined in the dimension of learning areas, it is revealed that curriculum in 2012 consists of four learning areas and curriculum in 2017 consists of five learning areas. The acquisitions related to ethics, confidentiality, security and digital citizenship in the learning area of Informatics Literacy in the curriculum of Informatics Technology and Software Development course in 2012 are categorized as a separate learning area in the name of Ethics and Security in the curriculum of the Informatics Technologies and Software Development in 2017. Learning areas of "Communicating with Informatics Technologies, Information Sharing, and Expressing the Self" and "Research, Configuration of the Information, and Collaborative Work" are combined as a learning area of "Communication, Research, and Cooperation". "Original Product Development" under the learning area of "Problem Solving, Coding, and Original Product Development" was presented as a separate learning area called "Digital Product Creation". In addition, Computational Thinking is a separate learning area in the Informatics Technology and Software Development course curriculum in 2017. The computational thinking was identified as one of the seven skills that today's students must possess by ISTE (2016). It is considered pedagogically important to include the Computational Thinking in the curriculum.

- It is seen that the acquisitions in Informatics Technologies and Software Development Course curricula in 2012 and 2017 are not significantly different when they are compared in terms of the dimension of acquisition. In addition, it was found out that the acquisitions related to cyberbullying were added to Ethics and Security unit in Informatics Technologies and Software Development curriculum in 2017.

- It was realized that Informatics Technologies and Software Development Course curricula in 2012 and 2017 adopted a process-oriented assessment approach. According to Shepard (2000), process-oriented assessment processes are based on constructivist approaches and make the student more active. For these reasons, it can be said that the right approach was chosen for the 2012 and 2017 curricula.

As a result of the study, it was found out that standards-based curriculum understanding was left with Informatics Technologies and Software Development Course curriculum in 2017 and separate units and acquisitions were generated for each grade. It was suggested that the general objectives of the informatics technologies and software development course are better expressed, the differences between the schools are tried to be eliminated by defining its content clearly, and teachers are offered three different approaches for teaching. Moreover, it is stated that the course can be applied for 1-4th graders within the free activity class time depending on student and parental desire and based on the readiness of students and individual proficiency level of teachers. It is considered that the most important of the problems can be experienced in the implementation of the program is that the courses will not be given as an elective and by an expert teacher for the classes. 


\section{Giriş}

Şerefoğlu, Henkoğlu ve Yıldırım’a (2012) göre bilişim teknolojilerindeki hızlı gelişmeler, bilginin toplumun her alanında kritik ve önemli bir rol üstlendiği "bilgi toplumu”nu oluşturmuştur. Çağımızın öncü kurumları Bilişim Teknolojileri'ni yoğun olarak kullanmaktadır. Bütün ülkelerde olduğu gibi bilgisayar okuryazarı bir toplum olmak ülkemizin de amacıdır. Okullarda Bilişim Teknolojileri eğitimi verilmesi, bu hedefe ulaşmada en önemli yollardan birini oluşturmaktadır (Duman, 2012). Akıncı ve Seferoğlu'na (2010) göre bilişim teknolojileri ile toplumumuzun düşünme, öğrenme ve iletişim alışkanlıkları gelecekteki ihtiyaçlara göre değiştirilmelidir. Bilgisayarın eğitimde kullanılmasının yanı sıra, bu aletlerin etik değerlere uygun ve doğru kullanımı büyük önem taşımaktadır. Bilişim Teknolojileri eğitimine gerekli önemin verilmesi, bireysel gelişimin yanı sıra toplumsal gelişimle, bilgiyi kullanan değil üreten olma, çağı yakalama ve çağa öncülük etmek için de bir hayli önemlidir (Karataş, Güneş ve Karabulut Coşkun, 2012). Türkiye'de bilgisayar ve internet erişiminin okullara getirilmesi, öğretmenlerin bilişim teknolojilerini kullanmalarına yönelik eğitilmesi ve bilişim teknolojilerinin eğitim sistemi ile bütünleşmesi çalışmaları 1998 yılından bu güne sürdürülmektedir (Çelebi Uzgur ve Aykaç, 2016). Türkiye'de "Bilgisayar" dersi ilköğretim okulları programında ilk kez 1998 yılında öğrencilerin bilgisayar okur-yazarı olmasını sağlamak amacıyla "Temel Eğitim Programı" kapsamında yer almıştır (EĞiTEK, 2001). 2006 yılında yapılan değişikliklerle bu dersin "seçmeli" olarak okutulmasına karar verilmiş, Talim Terbiye Kurulu (TTK) Başkanlı̆̆ı'nın kararıyla dersin ismi, "Bilişim Teknolojileri" olarak değiştirilmiştir (MEB, 2007a; TTK, 2006). Bilişim teknolojileri dersi, ders saatinde ya da öğretim programında çok sık değişiklik yapılmasına rağmen, sürekli seçmeli dersler arasında yer almıştr. Seçmeli Bilişim Teknolojileri dersi öğretim programı oluşturmacı yaklaşımı esas alarak iki bölümden oluşmakta; birinci bölümünde; giriş, programın vizyonu, temel yaklaşımı ve yapısı, öğrenme alanları, öğretim programının uygulama süreci, bilişim teknolojileri becerilerinin seviyelere göre performans göstergeleri, öğrenme-öğretme süreci, ölçme ve değerlendirme alt başlıkları yer alırken, öğretim programının ikinci bölümünde ise geliştirilen öğrenme alanları yer almaktadır (TTKB, 2006). Yapılan araştırmalarda dersin seçmeli oluşunun pedagojik açıdan birçok olumsuzluğa neden olduğu, derse verilen değeri azalttğı, dersin sadece bilişim teknolojileri sınıfi olan okullarda seçilebilmesinin ülkemizde bu alanda verilen eğitimin zayıf kalmasına sebep olduğu belirtilmiştir (Seferoğlu, 2007; Kabakçı, Kurt ve Yıldırım, 2008; Bektaş ve Semerci, 2008; Öztürk ve Yılmaz, 2011). 2012 yılında Milli Eğitim Bakanlığı tarafindan yayınlanan ders çizelgesinde ise dersin adı Bilişim Teknolojileri ve Yazııım olarak değişmiş, 2013-2014 eğitim-öğretim yılından itibaren zorunlu olarak ortaokul 5. ve 6. sınıflarda, seçmeli olarak 7. ve 8. sınıflarda okutulmaya başlamıştr. Ancak seçmeli ders için hazırlanan öğretim programı değiştirilmeden dersin zorunlu hale getirilmesinin ardından da aynen uygulanmaya devam edilmiştir (MEB; 2012). Bilişim teknolojileri ve yazılım dersi için genel standartlar belirlenmiş, Tomei'nin teknoloji alanı için yaptı̆̆ı taksonomi dikkate alınarak standartlara dayalı kazanımlar oluşturulmuştur. Düzeylere göre oluşturulan kazanımlara göre programın diğer öğelerinin tamamının öğretmen tarafından belirlemesi istenmiştir. Öğretim programı, bilgi okuryazarlığı, teknoloji kullanımında etik değerler, gizlilik, bilgi güvenliği ve sanal suçlar gibi kişisel ve toplumsal bakımdan dikkat edilmesi gerekenleri içermektedir. Bireylerin yeni teknolojileri kendi kendilerine öğrenebilmelerine ve yeni teknolojilerin doğru kullanımı konusunda kültür geliştirmelerine olanak sağlayan, ofis özdevimlerinin öğretildiği yapıdan uzak bir yaklaşım benimsenmiştir. (MEB, 2012).

Eğitim öğretimin verimliliği, öğretim programının etkililiği ile orantılıdır. Ülkeler, toplumda yaşanan değişimlere (toplumsal ihtiyaçların değişmesi, bilginin ve bilgi alışverişinin artması, teknolojinin ilerlemesi ve çağa ayak uydurma) uyum sağlamayı zaman içerisinde ya mevcut programlarını yeniden gözden geçirerek ya da yeni programlar geliştirerek gerçekleştirirler. Yaşadığımız çağda bilim ve teknolojinin sürekli gelişip, değişmesi ülkelerin bu değişime ayak uydurabilmeleri için eğitim programlarını sürekli olarak yenilemelerini zorunlu kılmıştır (Kaptan ve Kuşakcı, 2002). Program değerlendirme, program uygulanmadan önce hazırlanan bir eğitim programının güçlü ve zayıf yönlerini belirlemek üzere yapılabileceği gibi, programın uygulanması sırasında ya da sonrasında programın etkililiğini saptamak amacıyla da yapılabilir (Yüksel ve Sağlam, 2012).

Bilişim teknolojileri alanının diğer alanlardan çok daha hızlı geliştiği bilinen bir gerçektir. Bu nedenle bilişim teknolojileri ve yazılım dersi programının sürekli olarak değerlendirilmesi bir gereklilikten çok zorunluluk olarak görülmektedir. Bu bağlamda 2017 yılında Milli Eğitim Bakanlığı (MEB) Talim ve Terbiye Kurulu Başkanlığı, Ortaokul Bilişim Teknolojileri ve Yazılım Dersi Öğretim Programı'nda yenilemeye gitmiştir. Yenilenen öğretim programı bu alanda birçok yeniliği öğretme-öğrenme süreçlerine yansıtmayı amaçlamaktadır. Bu çalışmada 2017-2018 eğitim öğretim yılında uygulamasına başlanan Bilişim Teknolojisi ve Yazılım dersinin yeni öğretim programını değişik yönleriyle incelemeyi amaçlayan doküman incelemesidir. Bu inceleme yapılırken programın önceki programla yaklaşım, genel amaç, öğrenme alanları, kazanım, ölçme ve değerlendirme yaklaşımı açısından karşılaştırılması yapılmış, programın uygulamasında karşılaşılabilecek sorunlar ele alınmıştı. Uygulamaya konulan ders programının etkililiğini belirleyebilmek için bu tür araştırmaların gerekli olduğu düşünülmektedir. Alanyazında Bilişim Teknolojisi ve Yazılım dersi öğretim programlarının karşılaştııldığı 
çalışmalar çok sınırıdır. Daha çok öğretmen görüşlerinden yola çıkarak öneriler sunulan çalışmalar göze çarpmaktadır (Kural ve Güven, 2008; Öztürk ve Yılmaz, 2011; Çelebi Uzgur ve Aykaç, 2016). Çalışma bu anlamda programların tasarlanması, geliştirilmesi, değerlendirilmesi ve düzeltilmesi görevini yürüten Talim ve Terbiye Kurulu'nun çalışmalarına katkı sağlayabilir. Ayrıca çalışma yeni programın durumu ve niteliği hakkında araştırmacılara, alan uzmanlarına ve öğretmenlere bir perspektif sunmaktadır.

\section{Araştırmanın Amacı}

Araştırmanın amacı, Milli Eğitim Bakanlığı tarafından 2012 ve 2017 yıllarında yayınlanan Bilişim Teknolojileri ve Yazılım dersi öğretim programlarının yaklaşım, genel amaç, öğrenme alanları, kazanım, ölçme ve değerlendirme yaklaşımı açısından karşılaştırılmasıdır.

Araştırmada cevap aranan sorular ise şunlardır;

1. 2012 ve 2017 yıllarında yayınlanan Bilişim Teknolojileri ve Yazılım dersi öğretim programlarında yaklaşım boyutu nasıl ele alınmıştır?

2. 2012 ve 2017 yıllarında yayınlanan Bilişim Teknolojileri ve Yazılım dersi öğretim programlarında genel amaçlar nasıl ele alınmıştır?

3. 2012 ve 2017 yıllarında yayınlanan Bilişim Teknolojileri ve Yazılım dersi öğretim programlarında öğrenme alanları boyutu nasıl ele alınmıştır?

4. 2012 ve 2017 yıllarında yayınlanan Bilişim Teknolojileri ve Yazılım dersi öğretim programlarında kazanım boyutu nasıl ele alınmıştır?

5. 2012 ve 2017 yıllarında yayınlanan Bilişim Teknolojileri ve Yazııım dersi öğretim programlarında ölçme ve değerlendirme yaklaşımı boyutu nasıl ele alınmıştır?

\section{Araştırmanın problemi}

Öğretim programları herhangi bir dersin çıkış felsefesi, vizyonu, amaçları, öğretim yaklaşımı ve teknikleri, ölçme ve değerlendirme gibi ana hususlarını açıkladığından okullarda okutulan derslerin temelini oluşturur ve bir rehber niteliğindedir. 2017 yılında değişen Bilişim Teknolojisi ve Yazılım dersinin öğretim programı ile önceki programın yaklaşım, genel amaç, öğrenme alanları, kazanım, ölçme ve değerlendirme yaklaşımı açısından ne gibi farklııılar içerdiği araştırmanın problem durumunu oluşturmaktadır.

\section{Yöntem}

Araştırmanın soruları ve amacı doğrultusunda varolan durumu saptamak için nitel araştırma yöntemlerinden doküman inceleme tekniği seçilmiştir. Doküman incelemesi; araştıılması hedeflenen olgu hakkındaki yazılı ve görsel materyal ve malzemelerin belirli ölçütlere göre incelenmesi ve değerlendirilmesini kapsayan bir yöntemdir (Yıldırım ve Şimşek, 2005; Glesne, 2013). Bu süreç hem veri toplamayı hem de veri çözümlemesini içermektedir (Ekiz, 2009). Bu araştrrmada amaçlı örneklem türlerinden ölçüt örneklem kullanılmıştı. Bu amaçla, Milli Eğitim Bakanlığı tarafindan 2012 ve 2017 yıllarında yayınlanan Bilişim Teknolojileri ve Yazııım dersi öğretim programları içerik analizine tabi tutularak yaklaşım, genel amaç, öğrenme alanları, kazanım, ölçme ve değerlendirme yaklaşımı açısından incelenmiştir.

\section{Bulgular ve Yorumlar}

Araştırmada elde edilen veriler yaklaşım, genel amaç, öğrenme alanları, kazanım, ölçme ve değerlendirme yaklaşımı açısından ayrı ayrı değerlendirilmiştir.

\subsection{2 ve 2017 Bilişim Teknolojileri ve Yazılım Dersi Program Yaklaşımlarının Karşılaştırııması}

5 ve 6. sınıflarda zorunlu, 7 ve 8. sınıflarda seçmeli olarak okutulan 2012 Bilişim Teknolojileri ve Yazılım dersi öğretim programının, "standart tabanlı program" anlayışı ile hazırlandığı ve standartlara dayalı kazanımlar oluşturulurken Tomei'nin teknoloji alanı için oluşturduğu taksonominin dikkate alındığı görülmüştür. Eğitim alanındaki standartlar, öğretilmesi gereken bilgi ve yeterlikler dizisinin temeli olarak tanımlanabilir. Öğretmenler programı uygularken önce öğrencinin hangi düzeyde olduğunu belirleyecek, daha sonra öğrencinin düzeyini daha üste taşımayı hedefleyecektir. Amaç, her bir öğrencinin seviyesini yükselterek teknoloji kullanımı konusunda bir kültür oluşturmaktır. Programda sınıf düzeyleri için öğretilmesi gereken belirli bir ünite ve ya konu bulunmamakta, seçimler öğretmenin tercihlerine bırakılmaktadır.

2012 Bilişim Teknolojileri ve Yazılım dersi öğretim programında Shepard, Hannaway ve Baker, (2009)'un belirlediği

| Kastamonu Eğitim Dergisi, 27(1), 2019| 
standart özellikleri şu şekilde sıralanmıştr:

- Standartlar, öğrencilerin neleri anlaması ve yapabilmesi gerektiğini ana hatlarıyla belirler.

- Standartlar, gelecekteki iş ve eğitim gereksinimleriyle ilgili ve gelişimsel olarak öğrenciye uygun olmalıdır.

- Tüm öğrencilerin öğrenebileceğine ve yüksek beklentilere ulaşabileceğine inanılır.

- Öğretim sürecinde, standartların vurguladığı bilgi ve becerilerin her bir öğrenci tarafindan öğrenilmesine yardım edilir.

- Öğretme-öğrenme sürecinde etkin öğrenme vurgulanır.

- Öğrencilerin gerçek öğrenme başarılarına göre ilerlemesi sağlanır.

1- 4, 5, 6, 7 ve 8. sınıflar için geliştirilen 2017 Bilişim Teknolojileri ve Yazılım dersi öğretim programında ünite temelli yaklaşım esas alınmıştır. 1-4. sınıflar için verilen kazanımların öğrencilerin hazır bulunuşluk düzeyleri ve öğretmenlerin bireysel becerilerine bağlı olarak öğrenci ve veli istekleri doğrultusunda serbest etkinlik ders saati içerisinde uygulanması öngörülmüştür. Programda, 1-4 ve 5-8. sınıf düzeyinde beş temel ünite bulunmaktadır.

\subsection{2 ve 2017 Bilişim Teknolojileri ve Yazılım Ders Programlarının Genel Amaçlarının Karşılaştırılması}

2012 Bilişim Teknolojileri ve Yazılım dersi öğretim programının genel amacı; “Dersin sonunda öğrenciler, bilgi ve iletişim teknolojilerini etik değerlere uygun, etkili ve üretken bir biçimde kullanabilir" şeklinde ifade edilmiştir.

2017 Bilişim Teknolojileri ve Yazılım dersi öğretim programında ise genel amaç;

"Bu program öğrencilerin;

1. Dijital vatandaş olarak teknolojik kavramları, sistemleri ve işlemleri iyi anlayan bireyler olmalarını,

2. Bilişim teknolojilerini etkili ve amacına uygun kullanmalarını,

3. Internet tabanlı servislere erişmelerini, araştırmalarını ve kullanmalarını,

4. Bilgisayar bilimine ilişkin genel bir anlayış ve teknik birikim oluşturmalarını,

5. Problem çözme ve bilgi-işlemsel düşünme becerileri edinmelerini ve geliştirmelerini,

6. Akıl yürütme sürecini takip edebilmelerini ve değerlendirmelerini,

7. Öğrenme sürecinin bir parçası olarak işbirlikli çalışma becerileri edinmelerini, sosyal ortamlardan faydalanmalarını ve öğrendiklerini paylaşmalarını,

8. Internet ortamında öğrenme firsatları aramalarını,

9. Algoritma tasarımına ilişkin anlayış geliştirerek, sözel ve görsel olarak ifade edebilmelerini,

10. Problemleri çözmek için uygun programlama yaklaşımını seçerek uygulayabilmelerini,

11. Programlama konusunda teknik birikim oluşturmalarını,

12. Programlama dillerinden en az birini iyi düzeyde kullanabilmelerini,

13. Web sitesi tasarımı ve yönetimi konusunda çalışmalar yürütmelerini,

14. Günlük hayatta karşılaşılan sorunların (yaşı ve engelli bireylerin karşılaştı̆ı sorunlar vb.) çözümüne ilişkin yenilikçi ve özgün projeler geliştirmelerini,

15. Yaşam boyu öğrenme konusunda bilinç kazanmalarını amaçlamaktadır. " şeklinde belirtilmiştir.

Bilişim teknolojileri eğitiminin genel amaçları, 1739 sayılı Milli Eğitim Temel Kanunu'na göre belirlenen Türk Milli Eğitiminin genel amaçları çerçevesinde düşünülmeli, belirlenmeli ve yorumlanmalıdır.

Örneğin, bu temel yasada eğitimle her yurttaşın, “... hür ve bilimsel düşünme gücüne, geniş bir dünya görüşüne sahip, insan haklarına saygılı, kişilik ve teşebbüse değer veren, topluma karşı sorumluluk duyan; yapıcı, yaratıcı ve verimli kişiler olarak yetiştirilmesinin" alt çizilmektedir. Yukarıda yer alan yasanın genel çerçevesi içinde okullarda bilişim teknolojileri eğitiminin genel amaçlarını ve programın uygulamasını kısaca özetlemek, bazı noktaların önemini belirtmek gerekmektedir.

Bu bağlamda, içerik ve etkinlikler oluşturulurken gözetilecek ve dikkat edilecek noktalar 2017 Bilişim Teknolojileri ve Yazılım dersi öğretim programında aşağıdaki gibi yer almaktadır:

- Bu derste öğrenme süreci kuramsal bilginin yanı sıra mutlaka uygulama olanaklarıyla zenginleştirilmelidir.

- Öğrencinin öğrenme sürecine aktif olarak katılması sağlanmalıdır.

- Öğretmenin rolü; öğrencinin öğrenmesini kolaylaştırmak için ona rehberlik etmek, öğrencinin öğrenim sürecine katılımını sağlamak için gerekli önlemleri almak ve öğrenciyi sürekli güdülemek olmalı, hem bireysel hem de 
grup çalışmaları tercih edilmelidir.

- Bu süreçte ele alınan problemlerin ve çözüm önerilerinin doğrudan gerçek hayatla ilişkilendirilmesi ve gerçek bir probleme çözüm üretilmesi son derece önemlidir. Bu amaçla öğrenme sürecinin diğer derslerle ilişkilendirilmesi de önerilmektedir.

- Eğitim ortamı, öğrencileri öğrenmeye motive etmek ve öğrencilerin konuya ilgisini çekmek için öğrenmeye uygun olarak düzenlenmelidir.

- Paylaşmaya ve birlikte geliştirmeye dayalı sosyal kodlama ortamları da kullanılabilir. Bu ortamda öğrenciler ve öğretmenler kişisel ya da grup olarak yaptıkları yazılımları diğer; İnternet kullanıcıları ile paylaşmakta, bir proje üzerinde ortaklaşa çalışabilmekte ve mevcut projelerden yeni projeler üretebilmektedir.

- Bilişim Teknolojileri ve Yazılım Dersi'nde donanım olarak bilgisayarlar, tabletler ya da robot kitleri kullanılabilir.

- Teknik alt yapı eksiği bulunan okullarda öğrencilerin bilgisayar olmadan öğrenebilmeleri için farklı etkinliklerin ve uygulamaların yapılması önemlidir. Bilgisayar kullanmadan gerçekleştirilen etkinlikler ve drama süreçleri tasarlanıp uygulanabilir.

- Ayrıca; blok tabanlı programlama araçları, metin tabanlı programlama ortamları ve kağıt-kalem etkinlikleri (teknik alt yapı eksikliği olan okullar için bilgisayar kullanmadan) olmak üzere 3 yaklaşım sunulmuş, bu yaklaşımlara yönelik öğretim içerikleri ve etkinlikler geliştirilerek öğretmenlerin kendi tercihleri doğrultusunda bunlardan istediklerini uygulaması düşünülmüştür. Bu kapsamda geliştirilen öğretim içerikleri EBA (Eğitim Bilişim Ağı) altında yer alacaktır.

Yukarıdaki açıklamalardan anlaşıldığı gibi her okulda zümre öğretmenlerine yıllık ve günlük planlarını, ders işleniş örneklerini geliştirirken kalıplaşmış bir yapıya kendilerini kaptırmamaları önerilmekte; okullarındaki teknik alt yapıya göre farklı yaklaşımlarla ders kazanımlarının verilebileceği vurgulanmaktadır. Sadece bilişim teknolojileri üniteleri arasında bütünlük oluşturulması değil diğer ders konuları ve gerçek hayatla da konuların ilişkilendirilmesi sağlanmalı, böylece "bilişim teknolojileri ve yazılım dersi öğrenciye yarar sağlamaktadır", "teknolojiyi doğru kullanmayı öğrenmek önemlidir", "kodlama dersi ülke geleceği için önemlidir" gibi söylemler de uygulamada gerçekleştirilmelidir. Bu bilgiler ışığında, 2017 Bilişim Teknolojileri ve Yazılım dersi öğretim programı genel amaçlarının Türk Milli Eğitiminin genel amaçları çerçevesinde daha iyi ifade edildiği dikkati çekmektedir.

3.3. 2012 ve 2017 Bilişim Teknolojileri ve Yazılım Ders Programlarının Öğrenme Alanları Boyutunun Değerlendirilmesi

Tablo 1: 2012 ve 2017 Bilişim Teknolojileri ve Yazılım Dersi Programlarının Öğrenme alanları Boyutu

\begin{tabular}{|c|c|c|}
\hline Öğretim Yılı & Öğrenme Alanı Sayısı & Öğrenme Alanları İsimleri \\
\hline 2012 & 4 & $\begin{array}{l}\text { Bilişim Okur-Yazarlığı } \\
\text { Bilişim Teknolojilerini Kullanarak iletiş̧im Kurma, Bilgi } \\
\text { Paylaşma ve Kendini Ifade Etme } \\
\text { Araştrma, Bilgiyi Yapılandırma ve Iş̧birlikli Çalışma } \\
\text { Problem Çözme, Programlama ve Özgün Ürün Geliştirme }\end{array}$ \\
\hline 2017 & 5 & $\begin{array}{l}\text { Bilgi ve Iletişim Teknolojileri } \\
\text { Etik ve Güvenlik } \\
\text { Iletişim, Araştrma Ve İşbirliği } \\
\text { Dijital Ürün Olussturma } \\
\text { Hesaplamalı Düşünme }\end{array}$ \\
\hline
\end{tabular}

2012 ve 2017 Bilişim Teknolojileri ve Yazılım dersi öğretim programları öğrenme alanları boyutunda incelendiğinde 2012 öğretim programının dört öğrenme alanından, 2017 öğretim programının ise beş öğrenme alanından oluştuğu görülmektedir.

2012 Bilişim Teknolojileri ve Yazılım dersi öğretim programında Bilişim Okur-Yazarlığı öğrenme alanında yer alan etik, gizlilik, güvenlik ve dijital vatandaşlıkla ilgili kazanımların, 2017 Bilişim Teknolojileri ve Yazılım dersi programında Etik ve Güvenlik adı ile ayrı bir öğrenme alanı olarak belirlendiği dikkati çekmektedir. "Bilişim Teknolojilerini Kullanarak Illetişim Kurma, Bilgi Paylaşma ve Kendini İfade Etme" ve "Araştırma, Bilgiyi Yapılandırma ve İşbirlikli Çalışma" öğrenme alanları "iletişim, Araştırma ve İ̧̧birliği" öğrenme alanı olarak birleştirilmiştir. "Problem Çözme, Programlama ve Özgün Ürün Geliştirme" öğrenme alanı altında yer alan Özgün Ürün Geliştirme, "Dijital Ürün Oluşturma" adı ile ayrı bir öğrenme alanı olarak sunulmuştur. Ayrıca, Hesaplamalı Düşünme (Computational Thinking) 2017 Bilişim Teknolojileri ve Yazılım dersi öğretim programında ayrı bir öğrenme alanı olarak yer almaktadır. Hesaplı düşünme International Society for Technology Education (ISTE) (2016) tarafindan günümüz öğrencilerinin sahip olması gereken yedi beceriden biri 
olarak belirlenmiştir. Hesaplamalı Düşünmeye öğretim programında yer verilmesinin pedogojik açıdan önemli olduğu düşünülmektedir.

\subsection{2 ve 2017 Bilişim Teknolojileri ve Yazılım Ders Programlarının Kazanım Boyutunun Değerlendirilmesi}

\section{Tablo 2: 2012 ve 2017 Bilişim Teknolojileri ve Yazılım Dersi Programlarının Kazanım Boyutu}

\begin{tabular}{|c|c|c|c|c|c|c|c|c|c|c|c|}
\hline Öğretim Yılı & \multicolumn{6}{|c|}{2012 Yılı BTY Öğretim Programı } & \multicolumn{5}{|c|}{2017 Yılı BTY Öğretim Programı } \\
\hline Düzey & 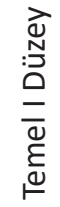 & 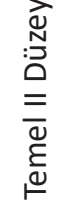 & 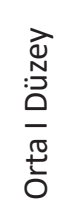 & 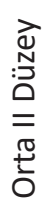 & 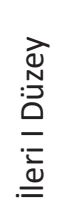 & $\begin{array}{l}\widehat{\widehat{N}} \\
: \underline{0} \\
\stackrel{=}{=}\end{array}$ & 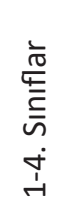 & 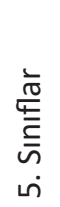 & 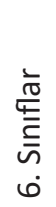 & 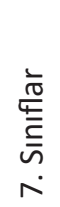 & 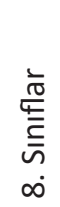 \\
\hline Kazanım Sa & 45 & 33 & 25 & 25 & 27 & 28 & 51 & 97 & 95 & 50 & 44 \\
\hline
\end{tabular}

2012 Bilişim Teknolojileri ve Yazılım öğretim programının; temel bilişim teknolojileri araçlarını tanıma ile başlayan, düşünme ve yaratıcılık becerileri ile ürün oluşturmaya kadar uzanan bir çerçeve program olduğu görülmektedir. Bu program temel, orta ve ileri seviyelerde, iki düzeylidir. Bunun yanı sıra hazırbulunuşlukları farklı öğrenciler için de aşamalı olarak bir üst düzeye yükselmesine olanak sağlanmaktadır.

2012 Bilişim Teknolojileri ve Yazılım Dersi öğretim programı ile 2017 Bilişim Teknolojileri ve Yazılım Dersi öğretim programı kazanım yönünden karşılaştııılıı̆ında kazanımların büyük ölçüde farklılaşmadığı, köklü reformların yaşanmadığı görülmektedir. Aşağıda iki programda da aynı olan kazanımlardan bazıları yer almaktadır:

Bilginin ağlar arasındaki yolculuğunu keşfeder. (2012, Temel I Düzey,2.1. İnternet, Iletişim)

Bilginin ağlar arasındaki yolculuğunu keşfeder. (2017, 5.3.1.1.1 İletişim, Araştırma ve İşbirliği)

Dosya uzantılarına göre dosyaların temel özelliklerini tanımlar.( 2012, Temel I Düzey,1.4. Biт'i Kullanma ve Yönetme)

Dosya uzantılarına göre dosyaların temel özelliklerini tanımlar.( 2017, 6.1.3.1. Dosya Yönetimi)

Elektronik verileri sınıflama ve saklama konusunda doğru yaklaşımları uygular. ( 2012, Orta I Düzey,1.4.

BiT'i Kullanma ve Yönetme)

Elektronik verileri sınıflama ve saklama konusunda doğru yaklaşımları uygular. (2017, 6.1.3.3. Dosya Yönetimi)

Kişisel mesaj ile dosyaların saklanması ve erişilmesi konusunda strateji geliştirir. ( 2012, ileri I Düzey,1.4.

BiT'i Kullanma ve Yönetme)

Dosyaların saklanması ve erişilmesi konusunda strateji geliştirir. (2017, 6.1.3.5. Dosya Yönetimi)

Etik ilkelerin ihlali sonucunda karşılaşılabilecek durumlara örnek verir. 2012, Temel I Düzey,1.6. BiT'ini Kul-

lanırken Etik ve Sosyal Değerler)

Etik ilkelerin ihlali sonucunda karşılaşılabilecek durumlara örnek verir. (2017, 6.2.1.5. Etik ve Güvenlik)

Ayrıca, 2017 Bilişim Teknolojileri ve Yazılım öğretim programında Etik ve Güvenlik ünitesine siber zorbalık konusuna ait kazanımlar eklendiği görülmüştür:

6.2.1.3. Siber zorbalık kavramını açıklayarak korunma amacıyla alınabilecek önlemleri tartışır.

Sanal ortamda karşılaşabilecek olumsuz davranışlara karşı duyarlı davranılması üzerinde durulur.

6.2.1.4. Siber zorbalığa maruz kaldığında ne yapacağını bilir.

8.2.1.2. Siber zorbalığın nedenlerini tartışır.

8.2.1.3. Siber zorbalığı azaltmak için yapılması gerekenleri açıklar.

ISTE'ye (2016) göre hesaplamalı düşünme, teknoloji ile düşünce birleşimini güçlendiren bir problem çözme yaklaşımıdır. Hesaplamalı Düşünme (computational thinking), çok geniş ve genel bir çerçeveye sahip olduğu göz önünde bulundurulduğunda sadece bilgisayarcılar için değil herkes için geçerli bir temel beceridir ve hesaplamalı düşünmenin yakın gelecekte herkes tarafindan kullanılan temel beceriler (okuma, yazma ve aritmetik gibi) arasında yer alacağı düşünülmektedir (Korkmaz vd.,2015). Bu nedenle 2017 öğretim programında Hesaplamalı Düşünme kavramının yer almasının öğretim programındaki en önemli değişiklik olduğu düşünülmektedir. Yine ISTE'ye (2016) göre eğitimde he- 
saplamalı düşünmenin amacının öğrencilerin bilgisayar biliminde ilerlemeleri değil, öğrencilerin bilgisayarca düşünme yeteneklerini bir alışkanlık gibi diğer derslerde de uygulamaları olduğu vurgulanmaktadır. Bu da Bilişim Teknolojileri ve Yazılım Dersinin diğer ders konuları ve gerçek hayatla da ilişkilendirilmesi açısından önemlidir.

2017 programında kazanımlar için öngörülen sürenin yeterli olduğu, kazanımların öğrenci seviyesine uygun olduğu, öğrencilerin günlük yaşam ihtiyaçları ile ilişkilendirilerek farklı öğrenme ihtiyaçlarına yanıt verdiği ve öğrencilerde merak uyandıracak içeriklere sahip olduğu görülmüştür. Dersin genel amaçları açısından kazanımlar uygundur.

3.5. 2012 ve 2017 Bilişim Teknolojileri ve Yazılım Ders Programlarının Ölçme ve Değerlendirme Yaklaşımlarının Karşılaştırılması

Tablo 3: 2012 ve 2017 Bilişim Teknolojileri ve Yazılım Dersi Programlarının Ölçme ve Değerlendirme Yaklaşımlarının Karşılaştırılması

\begin{tabular}{ccc}
\hline $\begin{array}{c}\text { Öğretim } \\
\text { Yılı }\end{array}$ & $\begin{array}{c}2012 \text { Yılı Bilişim Teknolojileri ve Yazılım } \\
\text { Dersi Öğretim Programı }\end{array}$ & $\begin{array}{c}\text { 2017 Yılı Bilişim Teknolojileri ve Yazılım } \\
\text { Dersi Öğretim Programı }\end{array}$ \\
\hline Portfolyo (e-portfolyo) & Portfolyo (e-portfolyo) \\
Rubrik değerlendirme & Rubrik değerlendirme \\
Öz değerlendirme & Öz ve akran değerlendirme formları \\
Performans değerlendirme & Performans ve Proje değerlendirme \\
\hline
\end{tabular}

2012 Bilişim Teknolojileri ve Yazılım Dersi öğretim programı ile 2017 Bilişim Teknolojileri ve Yazılım öğretim programında süreç odaklı değerlendirme yaklaşımı benimsendiği görülmüştür. Shepard’a göre (2000) süreç odaklı değerlendirme süreçleri, yapılandırmacı yaklaşımları temel almakta ve öğrenciyi daha etkin kılmaktadır. Öğrencilerin bilişsel ya da psikomotor bir ürün ortaya koymak için sınıf içi ya da dışında yaptı̆ı̆ı bütün etkinlikler ve gösterdiği çabalar değerlendirme kapsamında ele alınmaktadır. Kullanılacak ölçme aracı ve değerlendirme yaklaşımı olarak ölçülmek istenen becerilere ve değerlendirme sonuçlarının hangi amaçla kullanılacağına göre yukarıdaki süreç değerlendirme türlerinden herhangi biri belirlenebilmektedir. Değerlendirme sonrasında performansları hakkında verilen yapıcı geri bildirimler; öğrencilerin neyin önemli olduğunu, neyin öğretilmeye çalışıldığını ve hangi alanda gelişmek için çaba sarf etmeleri gerektiğini kavramalarını sağlayacaktı (MEB, 2017). Bu nedenlerle 2012 ve 2017 öğretim programlarında istenilen çıktıların değerlendirilmesi amacıyla doğru yaklaşımın seçildiği söylenebilir.

\section{Tartışma ve Sonuç}

Teknolojik gelişmeler hayatın birçok alanını etkilemektedir. Yeni teknolojiler her alanda kolaylaştırıcı çözümler sunduğundan, bireyler tarafindan kolaylıkla benimsenmekte ve vazgeçilmez hale dönüşmektedir. Günümüzde dijital vatandaş olarak isimlendirilen yeni nesil, teknolojik yeniliklerin içinde büyümekte küçük yaşlarından itibaren bu cihazları kullanabilme becerilerine sahiptirler. Günümüz dijital vatandaşlarına sunulan eğitim ortamlarının da onların gereksinimlerine uygun olacak şekilde tasarlanması çok önemlidir (Prensky, 2001; Thompson, 2013). Bu nedenle ülkerin birçoğu okulların teknoloji alt yapılarını güçlendirmek için yüksek bütçeli projeler gerçekleştirmektedir. Türkiye ise eğitimde son zamanların en yüksek bütçeli projesi olan FATiH (Fırsatları Artırma ve Teknolojiyi İyileştirme Hareketi) projesiyle okullardaki teknolojiyi iyileştirmeyi ve eğitim teknolojilerini derslerle etkin olarak bütünleştirmeyi hedeflemektedir. Bilişim Teknolojileri ve Yazılım Dersinin öğrenme ve öğretme sürecinin farklı teknolojik altyapılarla desteklenmesi gerekmektedir. 2017 Bilişim Teknolojileri ve Yazılım Dersi öğretim programında bilişim teknolojileri sınıf olmayan ve alt yapı problemi yaşayan okullar için ya da daha zengin öğrenme ortamları oluşturabilecek imkâna sahip okullar için blok tabanlı programlama araçları, metin tabanlı programlama ortamları ve kâğıt-kalem etkinlikleri - robotik kitler vb. gibi farklı yaklaşımlar kullanılabileceği önerilerek ders işlenişinin öğretmene bırakıldığı görülmüştür. Ayrıca, bu kapsamda geliştirilen öğretim içeriklerinin EBA (Eğitim Bilişim Ağı) altında yer alacağı vurgulanmıştır (MEB, 2017).

Araştırmanın sonucunda standart program anlayışından vazgeçildiği ve tüm sınıf düzeyleri için ayrı ayrı kazanımlar oluşturulduğu görülmüştür. Yapılan araştırmalara bakıldığında, 2012 Bilişim Teknolojileri ve Yazılım Dersi öğretim programında çerçeve program doğrultusunda her öğretmen kendi planını oluşturduğu için yakın çevredeki okullarda bile öğrencilerin derste öğrendiklerinin farklı olduğu, nakil gelen öğrenciler için bu durumun sorun oluşturduğu kısaca okullar arasında öğrenme farklılıkları olduğu görülmüştür (Çelebi Uzgur ve Aykaç, 2016). Ayrıca içeriklerin sınıf düzeylerinde birbirinin tekrarı olduğu dikkati çekmiştir. 2017 Bilişim Teknolojileri ve Yazııım Dersi öğretim programıyla birlikte 1-4 ve 5-8. sınıf düzeyinde beş temel ünite ve 02.10.2017 tarihinde MEB'in yayınladığı 5. Sınıf öğretmen ve öğrenci e-kitapları ve Bilişim Teknolojileri ve Yazııım Dersi öğretim materyalleri ile içeriğin net olarak belirlenerek okullar arasındaki öğren-

| Kastamonu Eğitim Dergisi, 27(1), 2019| 
me farklılıklarının ortadan kaldııımaya çalışıldığı dikkati çekmiştir.

Ayrıca 2017 Bilişim Teknolojileri ve Yazılım Dersi öğretim programında 1-4. sınıflar için verilen kazanımların öğrencilerin hazır bulunuşluk düzeyleri ve öğretmenlerin bireysel becerilerine bağlı olarak öğrenci ve veli istekleri doğrultusunda serbest etkinlik ders saati içerisinde uygulanabileceği belirtilmiştir. 1-4. sınıflar için dersin seçmeli ve uzman öğretmeni tarafindan verilmeyecek olmasının, programın uygulamasında yaşanabilecek sorunlardan en önemlisi olduğu düşünülmektedir. Yapılan araştırmalara göre dersin seçmeli oluşu öğrencilerin derse olan ilgi, istek ve ciddiyetlerinin azalması gibi çeşitli sorunları beraberinde getirmektedir (Bektaş, 2006; Seferoğlu, 2007; Öztürk ve Yılmaz, 2011). Öte yandan kodlama eğitimi öğrencilere yansıtıcılık, yaratıcılık, kural öğrenme ve kurallara uyma, problem çözme ve analitik düşünme, uzamsal düşünme becerileri gibi beceriler kazandırmaktadır (Akpınar ve Altun, 2014). Bu yönüyle ilkokullarda verilecek olan kodlama dersi amacının öğrencileri programcı olarak yetiştirmek olmadığı bu becerileri kazanmalarını sağlamak olduğu unutulmamalıdır. Bu nedenle Bilişim Teknolojileri ve Yazılım dersinin her kademede zorunlu ders olarak alan uzmanları tarafindan okutulması çağımızın bir gereği olarak görülmektedir.

2012 ve 2017 Bilişim Teknolojileri ve Yazılım dersi öğretim programları öğrenme alanları boyutunda incelendiğinde 2012 öğretim programının dört öğrenme alanından, 2017 öğretim programının ise beş öğrenme alanından oluştuğu görülmektedir. Hesaplamalı Düşünme (Computational Thinking) 2017 öğretim programında ayrı bir öğrenme alanı olarak yer almaktadır. Hesaplı düşünme ISTE tarafindan günümüz öğrencilerinin sahip olması gereken yedi beceriden biri (ISTE standart for students) olarak belirlenmiştir (ISTE, 2016). Hesaplamalı Düşünmeye öğretim programında yer verilmesinin öğrencilerin gelişimleri için önemli olduğu düşünülmektedir. ISTE'e (2016) göre öğrenciler, çözüm üretme ve geliştirmede teknolojik yöntemlerden faydalanarak problemleri anlama ve çözme stratejileri geliştirebilir ve kullanabilirler. Kısaca hesaplamalı düşünme, teknoloji ile düşünce birleşimini güçlendiren bir problem çözme yaklaşımıdır. Hesaplamalı Düşünmenin (computational thinking) çok geniş ve genel bir çerçevede olduğu göz önünde bulundurulduğunda yakın gelecekte herkes tarafindan kullanılan temel beceriler (okuma, yazma ve aritmetik gibi) arasında yer alacağı düşünülmektedir (Korkmaz vd., 2015). Bu nedenle 2017 öğretim programında Hesaplamalı Düşünme kavramının yer almasının öğretim programındaki en önemli değişiklik olduğu düşünülmektedir. Yine ISTE'e (2016) göre eğitimde hesaplamalı düşünmenin amacının öğrencilerin bilgisayar biliminde ilerlemeleri değil, öğrencilerin bilgisayarca düşünme yeteneklerini bir alışkanlık gibi diğer derslerde de uygulamaları olduğu vurgulanmaktadır. Bu da Bilişim Teknolojileri ve Yazılım Dersinin diğer ders konuları ve gerçek hayatla da ilişkilendirilmesi açısından önemlidir.

Ayrıca, 2017 Bilişim Teknolojileri ve Yazılım öğretim programında Etik ve Güvenlik ünitesinde siber zorbalık konusuna ait kazanımlar eklendiği görülmüştür.

2017 programında kazanımlar için öngörülen sürenin yeterli olduğu kazanımların öğrenci seviyesine uygun olduğu, öğrencilerin günlük ihtiyaçları ile ilişkilendirilerek farklı öğrenme ihtiyaçlarına cevap verdiği ve öğrencilerin merakını uyandıracak içeriklere sahip olduğu görülmüştür. Dersin genel amaçları açısından kazanımlar uygundur.

2012 Bilişim Teknolojileri ve Yazılım Dersi öğretim programı ile 2017 Bilişim Teknolojileri ve Yazılım öğretim programlarında süreç odaklı değerlendirme yaklaşımı benimsendiği görülmüştür. Süreç odaklı değerlendirme süreçleri, yapılandırmacı yaklaşımları temel almakta ve öğrenciyi daha etkin kılmaktadır (Shepard,2000). Öğrencilerin bilişsel ya da psikomotor bir ürün ortaya koymak için sınıf içi ya da dışında yaptı̆̆ı bütün etkinlikler ve gösterdiği çabalar değerlendirme kapsamında ele alınmaktadır (MEB, 2017). Bu nedenlerle 2012 ve 2017 öğretim programlarında doğru yaklaşımın seçildiği düşünülmektedir.

\section{Kaynakça}

Akbaba-Altun, S. (2006). Complexity of integrating computer technologies into education in Turkey. Educational Technology \& Society, 9(1), 176-187.

Akpınar, Y. ve Altun, A. (2014). Bilgi toplumu okullarında programlama eğitimi gereksinimi. illköğretim Online. 13(1).1-4

Akıncı, A. ve Seferoğlu, S. S. (2010). Bilişim şuraları, teknoloji politikaları ve eğitim. Akademik Bilişim'10 - XII. Akademik Bilişim Konferansı Bildirileri. 10 - 12 Şubat 2010, Muğla Üniversitesi, 475-482. 15.

Bektaş, C. (2006). İlköğretim okullarında bilgisayar derslerine ilişkin öğretmen görüşleri. Yüksek Lisans Tezi, Fırat Üniversitesi Sosyal Bilimler Enstitüsü Eğitim Bilimleri Anabilim Dalı, Elazığ.

Bektaş, C. ve Semerci, Ç. (2008). İlköğretim okullarında bilgisayar derslerine ilişkin öğretmen görüşleri (Elazığ ili örneği). Fırat Üniversitesi Sosyal Bilimler Dergisi, 18(1), 195-210.

Çelebi Uzgur, B. ve Aykaç, N. (2016). Bilişim teknolojileri ve yazılım dersi öğretim programının öğretmen görüşlerine göre değerlendirilmesi (Ege bölgesi örneği), Mustafa Kemal Üniversitesi Sosyal Bilimler Enstitüsü Dergisi, 13 (34), 273-297. 
Duman, H. (2012). Zorunlu formatörlük uygulaması ve bilişim teknolojileri öğretmenlerinin gelecekteki konumuna ilişkin öğretmen görüşleri (Adana ili örneği). Yayınlanmamış Yüksek Lisans Tezi. Çukurova Üniversitesi, Adana.

Eğitim Teknolojileri Genel Müdürlüğü [EĞiTEK]. (2001). Bakanlığımızca bilgisayar laboratuarı kurulan okullarda görev yapan müdür, müdür yardımcıları, formatör öğretmenler, bilgisayar öğretmenleri ve branş öğretmenlerinin bilgisayar laboratuarına ilişkin görev talimat. Ankara, MEB.

Ekiz, D. (2009). Bilimsel araştırma yöntemleri (Genişletilmiş 2.baskı), Anı Yayıncılık, Ankara.

Glesne, C. (2013). Nitel araştırmaya giriş, Ankara: Anı Yayıncılık, (Çev. A. Ersoy ve P. Yalçınoğlu), 2. Baskı.

ISTE (2016). Standards for students (ebook). https://www.iste.org/standards/for-students

Kabakçı, I., Kurt, A. ve Yıldırım, Y. (2008). Bilgisayar öğretmenlerinin seçmeli bilişim teknolojileri öğretim programının uygunluğuna ilişkin görüşlerinin belirlenmesi. VIII. Uluslar arası Eğitim Teknolojileri Konferansı. (sf.518-526). Eskişehir: Anadolu Üniversitesi.

Kaptan, F. ve Kuşakcı, F. (2002). Fen öğretiminde beyin firtınası tekniğinin öğrenci yaratıcılığına etkisi. V. Ulusal Fen Bilimleri ve Matematik Eğitimi Kongresi Bildiriler Kitabı (s. 197-202). ODTÜ : Ankara.

Karasar, N. (2002). Bilimsel araştırma yöntemleri. Ankara, Nobel Yayıncılık.

Karataş, S., Güneş, E.A., Karabulut Coşkun, B. (2012). Bilişim teknolojileri dersi ve ilköğretimde önemi. 6. Uluslararası Bilgisayar ve Öğretim Teknolojileri- 6th International Computer \& Instructional Technologies Symposium, Gaziantep, Turkey, 4-6 Oct. 2012, .

Korkmaz, Ö., Çakır, R., Özden, M. Y., Oluk, A., ve Sarıoğlu, S. (2015). Bireylerin bilgisayarca düşünme becerilerinin farklı değişkenler açısından incelenmesi. Ondokuz Mayıs Üniversitesi Eğitim Fakültesi Dergisi, 34(2), 68-87.

Kural Er, F. ve Güven, B. (2008). Illköğretim 6, 7 ve 8. sınıf bilgisayar dersi programının içeriğine ilişkin öğretmen görüşleri. Sosyal Bilimler Dergisi, 19, 175-184

Merrıam, S. B. (2013). Nitel araştırma: Desen ve uygulama için bir rehber (S. Turan,

Çev. Ed.) Nobel Yayınevi: Ankara. (Orijinal basım yılı 2009).

Milli Eğitim Bakanlığı [MEB]. (2007a). Yeni uygulamaya konulan ilköğretim kurumları derslerine ait öğretim programları ve haftalık ders saatleri çizelgesine ilişkin hususlar.

Öztürk, H. T. ve Yılmaz, B. (2011). Bilişim teknolojileri ve yazılım dersi'nin seçmeli statüsünün dersin pedagojik değerine yansımasının öğretmen bakış açısı ile değerlendirilmesi. Ege Eğitim Dergisi, 2(12), 63-821.

Prensky, M. (2001). Digital natives, digital immigrants. On the Horizon, 9(5), 1-2.

Seferoğlu, S. (2007). illköğretim bilgisayar dersi öğretim programı: eleştirel bir bakış ve uygulamada yaşanan sorunlar. Eğitim Araştırmaları Dergisi. 29; 99-111.

Şerefoğlu Henkoğlu, H. ve Yıldırım, S. (2012). Türkiye'deki ilköğretim okullarında bilgisayar eğitimi: kuram ve uygulamadaki farklılıklar, Ankara Üniversitesi Eğitim Bilimleri Fakültesi Dergisi, 45 (1), 23-61.

Shepard, L. A. (2000). The role of assessment in a learning culture. Educational Researcher, 29(7), 4-14.

Talim Terbiye Kurulu [TTK]. (2006). İlköğretim seçmeli bilgisayar (1-8. sınıflar) dersi öğretim programı. Ankara, MEB. Mart 29,

Yıldırım, A. Ve Şimşek, H. (2005). Sosyal bilimlerde nitel araştırma yöntemleri, Seçkin Yayınevi: Ankara.

Milli Eğitim Bakanlığı (MEB). (2012). Ortaokul ve imam hatip ortaokulu bilişim teknolojileri ve yazılım dersi (5, 6, 7 ve 8. sınıflar) öğretim programı.

Milli Eğitim Bakanlığı (MEB). (2017). Ortaokul ve imam hatip ortaokulu bilişim teknolojileri ve yazılım dersi (5, 6. Sınıflar) öğretim programı.

Öztürk, H. T. ve Yılmaz, B. (2011). Bilişim teknolojileri ve yazılım dersi'nin seçmeli statüsünün dersin pedagojik değerine yansımasının öğretmen bakış açısı ile değerlendirilmesi. Ege Eğitim Dergisi, 2(12), 63-821.

Thompson, P. (2013). The digital natives as learners: Technology use patterns and approaches to learning. Computers \& Education, $65,12-33$.

Yüksel, İ., ve Sağlam. M. (2012). Eğitimde program değerlendirme. Ankara: Pegem A Yayıncılık.

| Kastamonu Eğitim Dergisi, 27(1), 2019| 